\title{
Neighbourhood safety and leisure-time physical activity among Dutch adults: a multilevel perspective
}

\author{
Daniëlle Kramer ${ }^{1 *}$, Jolanda Maas ${ }^{2}$, Marleen Wingen ${ }^{3}$ and Anton E Kunst ${ }^{1}$
}

\begin{abstract}
Background: Several neighbourhood elements have been found to be related to leisure-time walking and cycling. However, the association with neighbourhood safety remains unclear. This study aimed to assess the association of neighbourhood-level safety with leisure-time walking and cycling among Dutch adults.

Methods: Data were derived from the national health survey (POLS) 2006-2009, with valid data on 20046 respondents residing in 2127 neighbourhoods. Multilevel logistic regression models were used to examine the association between neighbourhood-level safety (general safety and specific safety components: physical disorder, social disorder, crime-related fear, traffic safety) and residents' engagement in outdoor leisure-time walking and cycling for at least 30 minutes per week.

Results: An increase in neighbourhood safety (both general safety and each of the safety components) was significantly associated with an increase in leisure-time cycling participation. Associations were strongest for general safety and among older women. In the general population, neighbourhood safety was not significantly associated with leisure-time walking. However, among younger and older adult men and lower educated individuals, an increase in general safety was associated with a decrease in leisure-time walking participation.

Conclusions: In the Netherlands, neighbourhood safety appears to be related to leisure-time cycling but not to walking. Leisure-time cycling may best be encouraged by improving different safety components at once, rather than focusing on one safety aspect such as traffic safety. Special attention is needed for older women.
\end{abstract}

Keywords: Physical activity, Walking, Cycling, Safety, Crime, Environment

\section{Background}

Leisure-time walking and cycling may be appropriate types of physical activity (PA) to achieve current PA recommendations, since they are easy to implement in daily life with low cost and little risk of injury. The most effective ways to encourage these types of PA in adults are yet uncertain. Traditionally, focus has been on individual-level determinants of PA. Recently, a complementary ecological approach has been taken on which postulates that PA is also influenced by the individuals' living environment [1].

To create neighbourhood environments that encourage leisure-time walking and cycling, it is important to

\footnotetext{
*Correspondence: d.kramer@amc.uva.nl

'Department of Public Health, Academic Medical Centre, University of Amsterdam, PO Box 22660, Amsterdam 1100 DD, The Netherlands Full list of author information is available at the end of the article
}

understand which neighbourhood elements are most strongly related to these types of PA. According to a recent review, no firm conclusions can be drawn on environmental determinants of cycling due to lack of studies on this topic [2]. Leisure-time walking has been studied more extensively. Pedestrian infrastructure and neighbourhood aesthetics have consistently been found to be associated with leisure-time walking [3]. There is less consistent empirical support for other neighbourhood elements.

One of these elements is neighbourhood safety. Some studies have found a positive association between general neighbourhood safety and walking in leisure time [4,5], but most studies did not find an association [6-13]. Many of the studies on neighbourhood safety have used a composite measure, in which various safety components (e.g. traffic, crime, disorder) are combined into one comprehensive

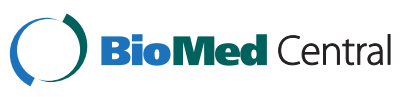


safety variable $[4,6,7,9-12]$. The use of such combined safety indicators might obscure the effects of the specific safety components.

Studies on specific safety components have most often explored the role of traffic safety. Inoue et al. [14] found that people who perceived good traffic safety were 1.5 times more likely to walk in leisure-time than those who perceived poor traffic safety. However, much other research has found inconsistent $[5,15,16]$ or no associations $[6,7,17-20]$ between traffic safety and walking. With regard to crime safety, again, results are inconsistent. Shigematsu et al. [18] found respondents' perceptions to be associated with leisure-time walking, but only in some age groups. Other studies have found no association at all $[6,14,17,20,21]$. Only few studies have explored the role of neighbourhood disorder. Cleland et al. [16] found limited evidence of a positive association with leisure-time walking. Absence of physical neighbourhood disorder was positively associated with maintaining high levels of leisuretime walking between baseline and follow-up, but not with three other leisure-time walking outcomes. Other studies did not find any significant association of leisure-time walking with indicators of neighbourhood disorder such as garbage, graffiti or public drunkenness [6,7].

Comparability of these results is limited, due to differences in settings, PA measures, and safety measures. Therefore, it is hard to determine the relative impact of each specific safety component on leisure-time walking behaviour. Studies are needed that simultaneously explore the association of various safety components with leisure-time walking. To our knowledge, there is only one American study that has explored multiple safety components [6]. The authors found no association between leisure-time walking and objective measures of criminal offenses, traffic-related offenses, physical disorder and social disorder.

As the latter study [6], most studies on safety and leisure-time walking have been performed in America and Australia [2,22]. European studies on this topic are rare. Yet, results may be different in Europe because PA patterns as well as the safety situation of neighbourhoods may differ $[23,24]$. For example, the association of leisuretime PA with crime and traffic safety may be less strong, because of safer traffic and lower crime rates in deprived neighbourhoods in Europe compared to America [23]. Within Europe, the Netherlands may be a particularly interesting country to explore the associations between neighbourhood safety and leisure-time PA. Due to high prevalence rates of walking and cycling [25], it offers the opportunity to explore the association of neighbourhood safety with both walking and the much less studied PA component cycling. The current evidence on the environmental correlates of cycling mainly comes from the transportation literature and has focused on cycling for transport rather than cycling in leisure time [17,20,26,27]. The one study on leisure-time cycling found no significant association with general safety [28].

The aim of the current study is to explore the association of neighbourhood-level safety with leisure-time walking and cycling in a large sample of Dutch adults. First, the association of general safety with leisure-time walking and cycling will be explored. Next, we will explore whether these associations are different for specific safety components. Following McGinn et al. [6], the safety components will include physical disorder, social disorder, crime-related fear and traffic safety. In a last step, we will explore whether associations differ by subpopulation. A review of Foster et al. [22] has postulated that associations may differ according to age, gender, education, and residential density of the neighbourhood. Women, elderly and lower educated tend to feel more vulnerable which may manifest itself in a stronger association of safety with leisure-time walking and cycling. Further, we postulate that in the Netherlands, densely populated areas may provide increased natural surveillance from both houses and pedestrians, which may make people feel less vulnerable to unsafe situations. If so, this would result in a weaker effect of safety on leisure-time walking and cycling in densely populated areas. Little research has focused on these differences.

\section{Methods \\ Study population}

Cross-sectional data on individual characteristics and leisure-time walking and cycling behaviour were obtained from the Dutch national health survey of 2006 to 2009, which is part of the yearly administered Dutch Integrated Survey on Household Living Conditions (POLS). A random nationwide sample of in total 57,281 non-institutionalized persons was drawn from the national population registry. Selected individuals were approached by an interviewer and asked to participate in an interview and, if 12 years and older, to fill in an additional paper-and-pencil survey on specific health topics, including PA. There was a nonresponse of $36 \%$ for the interview, with an additional 16\% non-response for the survey. Due to the age restriction, $16 \%$ of the sample was not eligible to complete the paperand-pencil survey. A total of 25.206 persons of 12 years and older completed the survey.

Cross-sectional data on residents' perceptions of neighbourhood safety were obtained using the three-yearly conducted Dutch Housing Questionnaire (WoON) of 2006. A random nationwide sample of 113,837 non-institutionalized adults (18 years and older) was approached by phone and asked to complete an interview either by phone, face to face, or on paper. There was a non-response of $42 \%$. A total of 64,005 adults from 3,495 neighbourhoods completed the survey. To assess the safety situation in each 
neighbourhood at large, we constructed neighbourhoodlevel safety scores by averaging the scores of all WoON respondents living in the same neighbourhood. Neighbourhoodlevel safety data from the WoON survey were linked to individual-level data from the Dutch national health survey using the 4-digit zipcode.

From the POLS data, we excluded respondents younger than $18(\mathrm{~N}=2,237)$, respondents whose neighbourhoodlevel safety scores have been based on less than five observations in the WoON survey $(\mathrm{N}=2,369)$ and respondents with unrealistic and missing PA scores $(\mathrm{N}=554$ for walking, $\mathrm{N}=566$ for cycling). PA scores were classified as unrealistic if the score exceeded 3360 minutes per week, which equals 8 hours each day of the week. A total remained of 20,046 POLS respondents with valid walking scores and 20,034 respondents with valid cycling scores, living in 2,127 neighbourhoods.

\section{Measures}

\section{Leisure-time walking and cycling}

Self-reported PA was measured in POLS using the Dutch Short QUestionnaire to ASsess Health-enhancing PA (SQUASH). This instrument has shown to be fairly reliable and valid, especially for large samples [29,30]. Respondents were asked to report the frequency (number of days) and duration (hours and minutes per day) of leisure-time walking and cycling and other PA activities in a typical week. Total minutes per week spent on walking and cycling in leisure time were calculated.

The distribution of leisure-time walking and cycling was highly skewed with $37 \%$ reporting zero minutes of leisuretime walking per week and $45 \%$ of respondents reporting zero minutes of cycling. Therefore, instead of using a continuous outcome measure, dummy variables were created for leisure-time walking and cycling by classifying respondents as 'inactive' (less than 30 minutes per week) versus 'active' (at least 30 minutes per week) levels. In other PA studies, respondents have often been classified on the basis of the WHO recommendation of 150 minutes per week. However, this 150 minutes cut-off point applies to overall levels of PA. In this study, we used a lower cut-off point because we focused on two specific components of PA (walking and cycling). Sensitivity analyses showed that the results of the present study are robust against alternative cut off points for leisure-time walking or cycling ( 0 or 60 minutes per week).

\section{Neighbourhood safety}

We measured four specific safety components, based on the distinctions made by McGinn et al. [6]: physical disorder, social disorder, crime-related fear and traffic safety.

- Physical disorder was assessed using the five items 'graffiti on walls and buildings', 'devastation of phone booths and bus-/tram booths', 'rubbish on the street', 'dog faeces on the street' and 'smell, dust and/or dirt'. All items used a three-point Likert scale ranging from 1 (often) to 3 (never). The physical disorder scale was computed by taking the average score of these five items. Alpha reliability analyses have been performed to determine the internal consistency of this scale. Cronbach's alpha was 0.73, indicating good reliability.

- Social disorder was assessed using the three items 'nuisance from direct neighbours', 'nuisance from other neighbourhood residents' and 'nuisance from youth'. All items used a three-point Likert scale ranging from 1 (often) to 3 (never). A social disorder scale was computed by taking the average score of these three items. Cronbach's alpha was 0.76 , indicating good reliability.

- Crime-related fear was assessed using the one item 'I am afraid to be troubled or robbed in this neighbourhood'. Answers were on a three-point Likert scale ranging from 1 (often) to 3 (never).

- Traffic safety was assessed using the one item 'I think the traffic situation in this neighbourhood is safe'. This item used a five-point Likert scale ranging from 1 (totally agree) to 5 (totally disagree). The two upper and lower scores have been combined, resulting in a three point Likert scale ranging from 1 (agree) to 3 (disagree).

All four safety variables were coded such that a higher score indicated higher perceived safety. The general safety scale has been composed by computing the average score on the four safety components. Cronbach's alpha was 0.68 , indicating fair reliability.

The measures above were constructed for the individual respondents of the WoON survey. Neighbourhood-level safety variables were constructed for each of the five safety measures by computing the average of the safety scores of all respondents living within the same 4-digit zipcode. All five neighbourhood-level safety variables were measured as continuous variables ranging from 1 (not safe) to 5 (very safe).

\section{Potential confounders}

Potential individual-level confounders that have been measured are age (continuous), gender, household composition (five categories), ethnicity (four categories) and socioeconomic status (SES). Three indicators of SES were included: education (five ordinal groups), disposable household income (five quintiles of net income in Euros) and disposable household wealth (five quintiles of the assembly of assets and debts in Euros). Age, gender, household composition and education have been assessed using the POLS questionnaire. Ethnicity was derived from the 
national population registry. Information on household income and wealth was obtained from the national tax registration. A potential neighbourhood-level confounder that has been included is population density (five ordinal groups). Population density has been estimated for each neighbourhood using data on the address density of the wider municipality. Data on address density has been derived from Statistics Netherlands.

\section{Statistical methods}

To take the sampling design of the POLS survey into account, prevalence of leisure-time walking and cycling were weighted for age, gender, marital status, household size, urbanization, province, and month of survey. The associations of (specific components of) neighbourhood safety with leisure-time walking and cycling were assessed by means of odds ratios derived from multilevel logistic regression analysis. Level 1 represented individuals, level 2 represented the neighbourhoods. A three-stage modelling approach was used to make a stepwise adjustment for age, gender, household composition, ethnicity (model 1), education, household income, household wealth (model 2) and population density (model 3 ). Each potential confounder was included as a set of dummy variables. Subpopulation analyses were performed using model 3. Potential effect-modification by age-gender, education and neighbourhood population density was investigated by entering interaction terms in the model. Intraclass Correlation Coefficient (ICC) was estimated using Rho to display the proportion of total variance in leisure-time walking and cycling that is attributable to the neighbourhood level. Associations were weighted using a complex survey sample design with sample weights. Results were almost identical to those presented below. For all analyses, statistical significance was set at 0.05 . Analyses were carried out using the STATA 11.0 software.

This study was based on secondary analyses of anonymized data by Statistics Netherlands (the "CBS"), with approval of the CBS authority for privacy protection. This authority has the responsibility to guarantee that all activities of the CBS are in strict agreement the Dutch laws for the protection of privacy of residents and subjects.

\section{Results}

Among the total adult population, the weighted prevalence of leisure-time walking was higher than of cycling (Table 1). More women than men engaged in leisure-time walking and cycling. Weighted prevalence of leisure-time walking and cycling among both groups increased with age up to 46-65 years old.

These age and gender differences in PA were found to be significant in multilevel logistic regression analyses (Table 2). Moreover, non-natives, married people, and higher educated people were significantly more likely to walk and cycle in leisure-time compared to their counterparts. Leisure-time cycling was positively associated with household wealth, but negatively associated with household income.

Table 3 shows that neighbourhood variations in levels of safety were most pronounced for traffic safety. The four specific safety components were highly to moderately correlated with each other, except for traffic safety.

Figure 1 shows to what amount the prevalence of leisure-time PA varied according to the level of general neighbourhood safety. The prevalence of leisure-time walking remained the same $(60 \%)$ across the range of general safety, while prevalence of leisure-time cycling increased from $40 \%$ in the most unsafe to $60 \%$ in the safest neighbourhoods.

Logistic regression analyses also show no strong association between neighbourhood safety and leisure-time walking (Table 4). The association was not statistically significant for general safety and the four specific safety components. In contrast, for leisure-time cycling, a positive and statistically significant association was found with both

Table 1 Weighted prevalence of leisure-time walking and cycling among the valid study population and various subgroups

\begin{tabular}{|c|c|c|c|c|c|}
\hline \multirow[b]{2}{*}{ Population (years) } & \multirow[b]{2}{*}{$\mathrm{N}$ with valid PA scores } & \multicolumn{2}{|l|}{ Leisure-time walking } & \multicolumn{2}{|l|}{ Leisure-time cycling } \\
\hline & & $\% \mathrm{~N} \geq 30 \mathrm{~min} /$ week & Mean min/week (SD) & $\% \mathrm{~N} \geq 30 \mathrm{~min} /$ week & Mean min/week (SD) \\
\hline Total adult population & 20046 & 61.9 & $158(265)$ & 52.5 & $131(267)$ \\
\hline Men 18-30 & 1492 & 42.8 & 97 (276) & 42.8 & 97 (267) \\
\hline Men 31-45 & 2542 & 58.5 & $121(232)$ & 48.8 & $90(214)$ \\
\hline Men 46-65 & 3557 & 64.6 & $169(254)$ & 54.1 & $140(288)$ \\
\hline Men > 65 & 1870 & 59.8 & $185(266)$ & 56.8 & $204(331)$ \\
\hline Women 18-30 & 1703 & 58.5 & $130(268)$ & 49.0 & $97(227)$ \\
\hline Women 31-45 & 2913 & 68.3 & 167 (272) & 57.7 & $126(266)$ \\
\hline Women 46-65 & 3718 & 70.4 & $196(289)$ & 60.8 & $160(276)$ \\
\hline Women > 65 & 2251 & 58.7 & $172(241)$ & 40.8 & $128(238)$ \\
\hline
\end{tabular}


Table 2 Association of individual and neighbourhood characteristics with leisure-time walking and cycling

\begin{tabular}{|c|c|c|c|}
\hline & \multirow[t]{2}{*}{$\% \mathbf{N}$} & \multicolumn{2}{|c|}{ Odds Ratio $(95 \% \mathrm{Cl})$ Model $3^{\mathrm{a}}$} \\
\hline & & Leisure-time walking & Leisure-time cycling \\
\hline \multicolumn{4}{|l|}{ Individual characteristics } \\
\hline Age (years) & $49 \pm 17$ & $1.01(1.01-1.01)^{*}$ & $1.00(1.00-1.00)$ \\
\hline \multicolumn{4}{|l|}{ Gender } \\
\hline Men & $47.2 \%$ & 1.00 & 1.00 \\
\hline Women & $52.8 \%$ & $1.46(1.38-1.55)^{*}$ & $1.18(1.12-1.25)^{*}$ \\
\hline \multicolumn{4}{|l|}{ Ethnicity } \\
\hline Native (Dutch) & $87.1 \%$ & 1.00 & 1.00 \\
\hline Non-native, Western & $6.4 \%$ & $1.19(1.06-1.35)^{*}$ & $0.84(0.75-0.95)^{*}$ \\
\hline Non-native, non-Western & $3.5 \%$ & $1.16(0.99-1.37)$ & $0.54(0.45-0.63)^{*}$ \\
\hline Non-native, origin unknown & $2.9 \%$ & $0.90(0.76-1.06)$ & $0.68(0.58-0.81)^{*}$ \\
\hline \multicolumn{4}{|l|}{ Household composition } \\
\hline Married/partner, no children & $37.8 \%$ & 1.00 & 1.00 \\
\hline Married/partner with child(ren) & $39.9 \%$ & $0.93(0.87-1.01)$ & $0.94(0.87-1.01)$ \\
\hline Single, no children & $17.2 \%$ & $0.74(0.68-0.81)^{*}$ & $0.77(0.71-0.84)^{*}$ \\
\hline Single with child(ren) & $4.4 \%$ & $0.70(0.60-0.81)^{*}$ & $0.75(0.65-0.87)^{*}$ \\
\hline Unknown & $0.8 \%$ & $0.59(0.43-0.80)^{*}$ & $0.77(0.56-1.06)$ \\
\hline \multicolumn{4}{|l|}{ Education } \\
\hline Tertiary education & $26.3 \%$ & 1.00 & 1.00 \\
\hline Secondary education: upper level & $35.5 \%$ & $0.73(0.67-0.79)^{*}$ & $0.79(0.74-0.86)^{*}$ \\
\hline Secondary education: mid level & $8.5 \%$ & $0.65(0.58-0.73)^{*}$ & $0.73(0.65-0.82)^{*}$ \\
\hline Secondary education: lower level & $14.8 \%$ & $0.58(0.52-0.64)^{*}$ & $0.73(0.66-0.81)^{*}$ \\
\hline Primary education & $14.6 \%$ & $0.42(0.38-0.47)^{*}$ & $0.48(0.43-0.53)^{*}$ \\
\hline Unknown & $0.3 \%$ & $1.08(0.61-1.91)$ & $0.63(0.38-1.06)$ \\
\hline \multicolumn{4}{|l|}{ Household income $(€)$} \\
\hline$>29.900$ & $20.9 \%$ & 1.00 & 1.00 \\
\hline $23.600-29.900$ & $20.5 \%$ & $1.02(0.93-1.12)$ & $1.04(0.95-1.14)$ \\
\hline $19.200-23.600$ & $20.1 \%$ & $1.00(0.91-1.10)$ & $1.15(1.04-1.26)^{*}$ \\
\hline $15.200-19.200$ & $19.8 \%$ & $1.03(0.93-1.13)$ & $1.21(1.09-1.33)^{*}$ \\
\hline$<15.200$ & $17.8 \%$ & $0.95(0.85-1.05)$ & $1.11(0.99-1.23)$ \\
\hline Unknown & $1.1 \%$ & $0.93(0.70-1.25)$ & $1.06(0.79-1.41)$ \\
\hline \multicolumn{4}{|l|}{ Household wealth $(€)$} \\
\hline$>293.469$ & $15.1 \%$ & 1.00 & 1.00 \\
\hline $148.000-293.469$ & $15.0 \%$ & $0.97(0.87-1.09)$ & $0.97(0.87-1.08)$ \\
\hline $39.047-148.000$ & $14.5 \%$ & $1.02(0.92-1.14)$ & $0.87(0.78-0.97)^{*}$ \\
\hline $3.362-39.047$ & $13.6 \%$ & $0.89(0.80-1.00)$ & $0.71(0.63-0.79)^{*}$ \\
\hline$<3.362$ & $12.2 \%$ & $1.00(0.89-1.13)$ & $0.70(0.62-0.79)^{*}$ \\
\hline Unknown & $29.6 \%$ & $1.02(0.92-1.13)$ & $0.83(0.75-0.91)^{*}$ \\
\hline \multicolumn{4}{|l|}{ Neighbourhood characteristics } \\
\hline \multicolumn{4}{|l|}{ Population density } \\
\hline Very dense & $16.5 \%$ & 1.00 & 1.00 \\
\hline Dense & $27.6 \%$ & $0.92(0.84-1.01)$ & $0.99(0.90-1.09)$ \\
\hline
\end{tabular}


Table 2 Association of individual and neighbourhood characteristics with leisure-time walking and cycling (Continued)

\begin{tabular}{lllr}
\hline Moderately dense & $21.8 \%$ & $0.97(0.88-1.08)$ & $1.03(0.93-1.14)$ \\
Slightly dense & $23.2 \%$ & $0.99(0.89-1.10)$ & $1.04(0.94-1.16)$ \\
Not dense & $10.9 \%$ & $1.03(0.91-1.17)$ & $0.97(0.85-1.10)$ \\
\hline
\end{tabular}

*p $\leq 0,05$.

${ }^{a}$ Adjusted for age, gender, ethnicity, household composition, education, household income, household wealth, population density.

general neighbourhood safety and each of the four specific safety components. A 1-unit increase in general neighbourhood safety was associated with a $40 \%$ increase in odds of leisure-time cycling. Associations with the specific safety components were somewhat weaker, and weakest for traffic safety. With a 1-unit increase in neighbourhood traffic safety, odds of leisure-time cycling increased by only $9 \%$. For all safety indicators, odds ratios of leisure-time walking and cycling changed to only a small extent after potential confounders were added to the model. Thus, measurable confounders appeared to have only a limited impact on the observed associations. The ICC shows that nearly one percent of the variance in leisure-time cycling is attributable to the neighbourhood-level, while there is no statistical support for between-neighbourhood differences in walking (Table 4).

Subpopulation differences in associations between general safety and leisure-time walking and cycling are presented in Table 5. For leisure-time walking, a significant inverse association with general safety was found for the youngest and oldest men and for the lower educated individuals. In these groups, an increase in general neighbourhood safety was related to a decrease in odds of leisuretime walking. For leisure-time cycling, the association with general neighbourhood safety was found to strengthen with increasing age. The association was also stronger for women compared to men of the same age. Cycling behaviour is most strongly related to safety for older women. The association between general safety and cycling appeared to be strongest with very dense populations, although interaction with population density was not statistically significant.

\section{Discussion}

In the present study, an increase in general neighbourhood safety and all specific safety components was found to be associated with an increase in leisure-time cycling participation. Associations were strongest for general safety and among older women. Overall, none of the neighbourhood safety outcomes was significantly associated with leisure-time walking. However, an increase in general neighbourhood safety was found to be associated with a decrease in leisure-time walking participation for the youngest and oldest adult men and for the lower educated people.

\section{Limitations}

The data available to this study had some potential limitations. First, while many potential confounders at the individual level have been accounted for, not all neighbourhood-level factors have taken into account that may have confounded the association between safety and PA. For example, an area with mixed land use and nearby shopping and recreational facilities may stimulate leisure-time walking, while such an area might at the same time be relatively unsafe. In the present study, confounding by such factors may have concealed an association between safety and leisure-time walking. In order to address this potential source of bias, we have adjusted our analyses for population density, as this variable may correlate with land use mix and the proximity of facilities. We found that control for population density had negligible effects on the associations between safety and walking or cycling. Future research should aim to control for neighbourhood-level confounders in more detail.

There was a non-response of $36 \%$ for the POLS interview and another $16 \%$ for the additional paper-and-pencil survey. Non-respondents may have differed in important aspects from the study population. However, this would only have biased the results of this study if non-response varied according to the level of individual PA, as well as

Table 3 Mean neighbourhood-level safety scores and the correlation between safety variables

\begin{tabular}{llllll}
\hline Safety variables & Mean (SD) & Range & \multicolumn{2}{l}{ Pearson correlation coefficient } \\
\cline { 5 - 5 } & & & General safety & Physical disorder & Social disorder \\
\hline General safety & $4.35(0.28)$ & $2.81-4.97$ & & \\
Physical disorder & $4.24(0.35)$ & $2.83-4.95$ & 0.80 & 0.68 & 0.53 \\
Social disorder & $4.49(0.30)$ & $3.15-4.96$ & 0.76 & 0.56 & 0.24 \\
Crime-related fear & $4.65(0.37)$ & $2.08-4.96$ & 0.73 & 0.28 & 0.17 \\
Traffic-safety & $4.01(0.50)$ & $1.67-4.89$ & 0.66 & & 0.24 \\
\hline
\end{tabular}




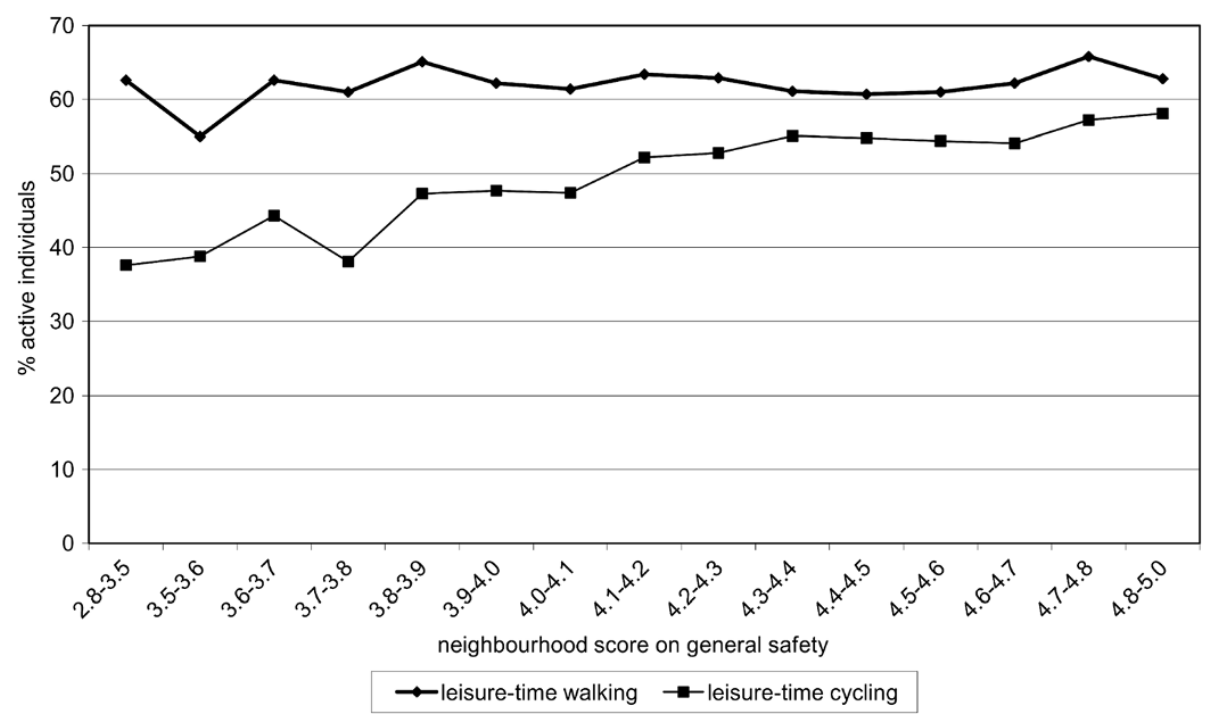

Figure 1 Weighted percentage of individuals engaging in leisure-time walking or cycling for at least $\mathbf{3 0}$ minutes per week, by level of general neighbourhood safety.

the degree of neighbourhood safety, after accounting for confounders. We think this is not very likely, but we can not entirely exclude the possibility of some bias.

Another limitation has to do with the self-reported nature of PA. People may have difficulty estimating their time spent on PA and may be inclined to give socially desirable answers, which might have caused them to overestimate their levels of PA [31]. However, this only becomes a problem if the amount of overestimation differs between safe and unsafe neighbourhoods after controlling for individual-level confounders. Again, we think this is not very likely.

Neighbourhood safety was also self-reported. We chose to use subjective measures of neighbourhood safety, because there is evidence that objective and subjective ratings are poorly correlated $[16,32]$ and that subjective ratings

Table 4 Association of general safety and specific safety components with leisure-time walking and -cycling

\begin{tabular}{|c|c|c|c|}
\hline & \multicolumn{3}{|l|}{ Odds ratio $(95 \% \mathrm{Cl})$} \\
\hline & $\begin{array}{l}\text { Model } 1 \text { (age, gender, ethnicity, } \\
\text { household comp.) }\end{array}$ & $\begin{array}{l}\text { Model } 2 \\
\text { (+education, income, wealth) }\end{array}$ & $\begin{array}{l}\text { Model } 3 \\
\text { (+population density) }\end{array}$ \\
\hline \multicolumn{4}{|l|}{ Leisure-time walking } \\
\hline General safety & $0.96(0.86-1.08)$ & $0.95(0.85-1.06)$ & $0.92(0.81-1.05)$ \\
\hline Physical disorder & $0.94(0.86-1.03)$ & $0.94(0.86-1.03)$ & $0.90(0.81-1.01)$ \\
\hline Social disorder & $0.94(0.84-1.04)$ & $0.95(0.85-1.05)$ & $0.92(0.82-1.04)$ \\
\hline Crime-related fear & $0.98(0.90-1.06)$ & $0.98(0.90-1.06)$ & $0.97(0.88-1.06)$ \\
\hline Traffic safety & $1.02(0.95-1.09)$ & $1.00(0.94-1.07)$ & $1.00(0.93-1.06)$ \\
\hline \multicolumn{4}{|l|}{ Leisure-time cycling } \\
\hline General safety & $1.50(1.34-1.68)^{*}$ & $1.42(1.27-1.59)^{*}$ & $1.40(1.23-1.60)^{*}$ \\
\hline Physical disorder & $1.34(1.22-1.47)^{*}$ & $1.28(1.17-1.41)^{*}$ & $1.27(1.14-1.42)^{*}$ \\
\hline Social disorder & $1.31(1.18-1.46)^{*}$ & $1.27(1.14-1.41)^{*}$ & $1.22(1.08-1.37)^{*}$ \\
\hline Crime-related fear & $1.29(1.19-1.40)^{*}$ & $1.26(1.16-1.37)^{*}$ & $1.23(1.12-1.35)^{*}$ \\
\hline Traffic safety & $1.13(1.05-1.20)^{*}$ & $1.10(1.04-1.18)^{*}$ & $1.09(1.02-1.17)^{*}$ \\
\hline \multicolumn{4}{|c|}{ Intraclass Correlation Coefficient } \\
\hline Leisure-time walking & $0.00(0.00-0.04)$ & $0.00(0.00-0.62)$ & $0.00(0.00-0.99)$ \\
\hline Leisure-time cycling & $0.01(0.01-0.02)^{*}$ & $0.01(0.00-0.02)^{*}$ & $0.01(0.00-0.02)^{*}$ \\
\hline
\end{tabular}

${ }^{*} p \leq 0.05$. 
Table 5 Association of general safety with leisure-time walking and cycling in different subgroups

\begin{tabular}{|c|c|c|c|c|}
\hline & \multicolumn{2}{|l|}{ Leisure-time walking } & \multicolumn{2}{|l|}{ Leisure-time cycling } \\
\hline & Odds ratio $(95 \% \mathrm{Cl})$ & $\mathrm{p}$-value of interaction & Odds ratio $(95 \% \mathrm{Cl})$ & $\mathrm{p}$-value of interaction \\
\hline \multicolumn{5}{|l|}{ Age-gender category } \\
\hline Men 18-30 years & $0.42(0.27-0.65)^{*}$ & Reference & $1.25(0.80-1.94)$ & Reference \\
\hline Men 31-45 years & $0.90(0.67-1.21)$ & $<0.01^{*}$ & $1.25(0.93-1.69)$ & 0.99 \\
\hline Men 46-65 years & $1.15(0.87-1.51)$ & $<0.01^{*}$ & $1.37(1.04-1.80)^{*}$ & 0.72 \\
\hline Men $>65$ years & $0.65(0.45-0.93)^{*}$ & 0.14 & $1.53(1.06-2.19)^{*}$ & 0.48 \\
\hline Women $18-30$ years & $1.12(0.76-1.64)$ & $<0.01^{*}$ & $1.01(0.69-1.48)$ & 0.47 \\
\hline Women $31-45$ years & $1.20(0.90-1.60)$ & $<0.01^{*}$ & $1.39(1.05-1.84)^{*}$ & 0.68 \\
\hline Women $46-65$ years & $1.06(0.80-1.42)$ & $<0.01^{*}$ & $1.74(1.32-2.30)^{*}$ & 0.20 \\
\hline Women $>65$ years & $1.02(0.73-1.43)$ & $<0.01^{*}$ & $2.23(1.57-3.16)^{*}$ & $0.04^{*}$ \\
\hline \multicolumn{5}{|l|}{ Educational level $^{\mathrm{a}}$} \\
\hline Higher educated & $1.04(0.88-1.22)$ & Reference & $1.37(1.17-1.61)^{*}$ & Reference \\
\hline Lower educated & $0.79(0.66-0.95)^{*}$ & $0.02^{*}$ & $1.48(1.22-1.78)^{*}$ & 0.51 \\
\hline \multicolumn{5}{|l|}{ Population density } \\
\hline Very dense & $0.98(0.75-1.27)$ & Reference & $1.70(1.30-2.23)^{*}$ & Reference \\
\hline Dense & $0.96(0.76-1.21)$ & 0.91 & $1.33(1.05-1.68)^{*}$ & 0.17 \\
\hline Moderately dense & $0.89(0.67-1.19)$ & 0.64 & $1.41(1.06-1.88)^{*}$ & 0.34 \\
\hline Slightly dense & $0.84(0.60-1.18)$ & 0.50 & $1.24(0.88-1.74)$ & 0.15 \\
\hline Not dense & $0.86(0.55-1.34)$ & 0.62 & $1.23(0.79-1.92)$ & 0.22 \\
\hline
\end{tabular}

${ }^{*} p \leq 0,05$.

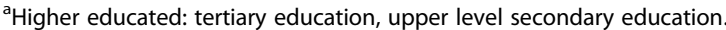

Lower educated: mid and lower level secondary education, primary education.

may be more important in determining PA behaviour $[32,33]$. Those in favour of objective measures, have argued that objective measures are needed to avoid bias associated with self-reports, such as the 'single source bias' [34]. This source of bias may occur if self-reported data on both determinants and outcomes are collected using the same survey. To avoid this source of bias, we have used two different sets of respondents for measuring neighbourhood safety (the WoON survey) and leisure-time walking and cycling (the POLS survey).

\section{Interpretation of key results}

Associations between safety and leisure-time cycling have been found to be strongest for general safety. This suggests that a combination of safety problems may have more impact on people's engagement in cycling than isolated safety problems. The weakest association with cycling has been found for traffic safety. This supports an earlier study that found traffic safety to have less influence on leisure-time PA than other safety components [6]. The weak association for traffic safety is remarkable as neighbourhood variations in levels of safety were most profound for traffic safety (Table 2). Results of the present study suggest that people are more influenced by social aspects of safety such as crime and social disorder, than by traffic safety.
Subgroup analyses suggested that elderly women were most influenced by general neighbourhood safety in their cycling behaviour. This supports earlier research $[22,35]$. Foster et al. [22] suggest that women and elderly may be more sensitive to safety as they feel more physically vulnerable than men and young adults.

The positive association between neighbourhood safety and cycling may in part reflect a safety component that has not been included: fear of bicycle theft or damage. This seems to be a plausible mechanism since bicycle theft rates among bicycle owners in the Netherlands are the highest in the world [24].

Leisure-time walking was not significantly associated with general neighbourhood safety or any of its safety components. An American study that used various objectively measures safety components, yielded the same results [6]. Many other studies, too, did not find an association between safety and leisure-time walking [6-13,17,20,21]. Some evidence of an association was found in other studies, but results were mostly inconsistent $[4,5,14-16,18,19]$.

Lack of a positive association in the present study might have been due to focus on fairly large neighbourhoods. 4-digit zip code areas have an average of 4.088 inhabitants [36]. Environmental influences of safety on walking may have been more apparent on a smaller scale, since walking is primarily performed in the immediate area around the 
home. Future research should assess if a focus on smaller areas reveals a more significant association.

Subgroup analyses have shown an inverse relationship between safety and leisure-time walking for young men and for lower educated. Earlier studies support this finding $[18,37,38]$. Ross et al. [38] suggest that unsafe neighbourhoods have a culture of being outside on the streets, which may be especially attractive to these groups.

\section{Conclusions}

The current study indicates that, in the Netherlands, a safe neighbourhood may increase adults' participation in leisure-time cycling but not necessarily in walking. Leisure-time cycling may best be encouraged by improving different safety components at once, rather than focusing on one aspect such as traffic safety. Special attention needs to be paid to residents that are particularly sensitive to the safety situation in the neighbourhood, such as older women.

\section{Competing interests}

The authors declare that they have no competing interests.

\section{Authors' contributions}

DK and AK developed the study design. MW and DK prepared the data. DK performed the analyses and, with help of AK, drafted the manuscript. JM and MW revised intermediate results and manuscript versions and made substantial contributions to subsequent versions. All authors have read and approved the final version of the manuscript.

\section{Acknowledgements}

This research was part of the URBAN40 study, which is supported by a grant from The Netherlands Organisation for Health Research and Development (ZonMW). We gratefully acknowledge Statistics Netherlands for preparing micro-level data of POLS and for providing access to these data. We would also like to thank the Data Archiving and Networked Services (DANS) that made the free use of WoON 2006 possible.

\section{Author details}

1Department of Public Health, Academic Medical Centre, University of Amsterdam, PO Box 22660, Amsterdam 1100 DD, The Netherlands. ${ }^{2}$ Department of Public and Occupational Health, and the EMGO Institute for Health and Care Research, VU University Medical Centre, Amsterdam, the Netherlands. ${ }^{3}$ Department of Social and Spatial Statistics, Statistics Netherlands, Heerlen, the Netherlands.

Received: 7 March 2012 Accepted: 22 January 2013 Published: 28 January 2013

\section{References}

1. Sallis JF, Cervero RB, Ascher W, Henderson KA, Kraft MK, Kerr J: An ecological approach to creating active living communities. Annu Rev Public Health 2006, 27:297-322.

2. Wendel-Vos W, Droomers M, Kremers S, Brug J, Lenthe van F: Potential environmental determinants of physical activity in adults: a systematic review. Obes Rev 2007, 8:425-440.

3. Saelens B, Handy SL: Built environment correlates of walking: a review. Med Sci Sports Exerc 2008, 40:550-566.

4. Giles-Corti B, Donovan RJ: Socioeconomic status differences in recreational physical activity levels and real and perceived access to a supportive physical environment. Prev Med 2002, 35:601-611.

5. Cao X, Handy SL, Mokhtarian PL: The influences of the built environment and residential self-selection on pedestrian behavior: evidence from Austin, TX. Transportation 2006, 33:1-20.
6. McGinn AP, Evenson KR, Herrin AH, Huston SL, Rodriguez DA: The association of perceived and objectively measured crime with physical activity: a cross-sectional analysis. J Phys Act Health 2008, 5:117-131.

7. Hallal PC, Reis RS, Parra DC, Hoehner C, Brownson RC, Simoes EJ: Association between perceived environmental attributes and physical activity among adults in Recife, Brazil. J Phys Act Health 2010, 7:213-222.

8. Kamphuis CBN, van Lenthe FJ, Giskes K, Huisman M, Brug J, Mackenbach JP: Socioeconomic differences in lack of recreational walking among older adults: the role of neighbourhood and individual factors. Int J Behav Nutr Phys Act 2009, 6. doi:10.1186/1479-5868-6-1.

9. Mendes de Leon CF, Cagney KA, Bienias JL, Barnes LL, Skarupski KA, Scherr $P A$, et al: Neighbourhood social cohesion and disorder in relation to walking in community-dwelling older adults: a multilevel analysis. J Aging Health 2009, 21:155-171.

10. Gauvin L, Riva M, Barnett T, Richard L, Craig CL, Spivock M, et al: Association between neighbourhood active living potential and walking. Am J Epidemiol 2007, 167:944-953.

11. Ball K, Timperio A, Salmon J, Giles-Corti B, Roberts R, Crawford D: Personal, social and environmental determinants of educational inequalities in walking: a multilevel study. J Epidemiol Comm Health 2007, 61:108-114.

12. Pikora T, Giles-Corti B, Knuiman MW, Bull FC, Jamrozik K, Donovan RJ: Neighbourhood environmental factors correlated with walking near home: using SPACES. Med Sci Sports Exerc 2006, 38:708-714.

13. van Lenthe FJ, Brug J, Mackenbach JP: Neighbourhood inequalities in physical inactivity: the role of neighbourhood attractiveness, proximity to local facilities and safety in the Netherlands. Soc Sci Med 2005, 60:763-775

14. Inoue S, Ohya Y, Odagiri Y, Takamiya T, Ishii K, Kitabayashi M, et al: Association between perceived neighbourhood environment and walking among adults in 4 cities in Japan. J Epidemiol 2010, 20:277-286.

15. Nagel CL, Carlson NE, Bosworth M, Michael YL: The relation between neighbourhood built environment and walking activity among older adults. Am J Epidemio/ 2008, 168:461-468.

16. Cleland VJ, Timperio A, Crawford D: Are perceptions of the physical and social environment associated with mothers' walking for leisure and for transport? A longitudinal study. Prev Med 2008, 47:188-193.

17. van Dyck D, Cardon G, Deforche B, Giles-Corti B, Sallis JF, Owen N, et al Environmental and psychosocial correlates of accelerometer-assessed and self-reported physical activity in Belgian adults. Int J Behav Med 2010, 18:235-245.

18. Shigematsu R, Sallis JF, Conway $T L$, Saelens BE, Frank LD, Cain KL, et al: Age differences in the relation of perceived neighborhood environment and walking. Med Sci Sports Exerc 2009, 41:314-321.

19. McGinn AP, Evenson KR, Herrin AH, Huston SL, Rodriguez DA: Exploring associations between physical activity and perceived and objective measures of the built environment. J Urban Health 2007, 84:162-184.

20. de Bourdeaudhuij I, Teixeira PJ, Cardon G, Deforche B: Environmental and psychosocial correlated of physical activity in Portugese and Belgian adults. Public Health Nutr 2005, 8:886-895.

21. Foster C, Hillsdon M, Jones A, Grundy C, Wilkinson P, White M, et al: Objective measures of the environment and physical activity - results of the environment and physical activity study in English adults. J Phys Act Health 2009, 6:70-80.

22. Foster S, Giles-Corti B: The built environment, neighbourhood crime and constrained physical activity: an exploration of inconsistent findings. Prev Med 2008, 47:241-251.

23. Bassett DR, Pucher J, Buehler R, Thompson DL, Crouter SE: Walking, cycling, and obesity rates in Europe, North America, and Australia. J Phys Act Health 2008, 5:795-814.

24. van Dijk J, van Kestern J, Smit P: Criminal victimization in international perspective: key findings from the 2004-2005 ICVS and EU ICS. Meppel: Boom juridical publishers; 2007.

25. Pucher J, Buehler R: Making cycling irresistible: lessons from the Netherlands, Denmark and Germany. Transp Rev 2008, 28:495-528.

26. Titze S, Stronegger WJ, Janschitz S, Oja P: Association of built -environment, social-environment and personal factors with bicycling as a mode of transportation among Austrian city dwellers. Prev Med 2008, 47:252-259.

27. de Geus B, de Bourdeaudhuij I, Jannes C, Meeusen R: Psychosocial and environmental factors associated with cycling for transport among a working population. Health Educ Res 2008, 23:697-708. 
28. Kamphuis CBM, Giskes K, Kavanagh AM, Thornton LE, Thomas LR, van Lenthe FJ, et al: Area variation in recreational cycling in Melbourne: a compositional or contextual effect? J Epidemiol Comm Health 2008, 62:890-898.

29. Wagenmakers R, Akker-Scheek I, Groothoff JW, Zijlstra W, Bulstra SK, Kootstra $J W J$, : Reliability and validity of the short questionnaire to assess healthenhancing physical activity (SQUASH) in patients after total hip arthroplasty. BMC Musculoskelet Disord 2008, 9. doi:10.1186/1471-2474-9-141.

30. Wendel-Vos GCW, Schuit AJ, Saris WHM, Kromhout D: Reproducibility and relative validity of the short questionnaire to assess health-enhancing physical activity. I Clin Epidemiol 2003, 56:1163-1169.

31. Shephard RJ: Limits to the measurement of habitual physical activity by questionnaires. Br J Sports Med 2003, 37:197-206.

32. Gebel K, Bauman A, Owen N: Correlates of non-concordance between perceived and objective measures of walkability. Ann Behav Med 2009, 37:228-238.

33. Ball K, Cleland VJ, Timperio AF, Salmon J, Giles-Corti B, Crawford DA: Love thy neighbour? Associations of social capital and crime with physical activity amongst women. Soc Sci Med 2010, 71:807-814.

34. King WC, Belle SH, Brach JS, Simkin-Silverman LR, Soska T, Kriska AM: Objective measures of neighborhood environment and physical activity in older women. Am J Prev Med 2005, 28:461-469.

35. Shenessa ED, Liebhaber A, Ezeamama A: Perceived safety of area of residence and exercise: a pan-European study. Am J Epidemiol 2006, 163:1012-1017.

36. Statistics Netherlands: Bevolking en huishoudens: viercifferige postcode. [http.// statline.cbs.nl/StatWeb/publication/defaultaspx?DM=SLNL\&PA=71899NED\&D1=0\% $2 c 21 \% 2 c 42 \% 2 c 63-72 \& D 2=a \& H D R=T \& S T B=G 1 \& W=D]$.

37. Humpel N, Owen N, Iverson D, Leslie E, Bauman A: Perceived environment attributes, residential location, and walking for particular purposes. Am J Prev Med 2004, 26:119-125.

38. Ross CE: Walking, exercising, and smoking: does neighbourhood matter? Soc Sci Med 2000, 51:265-274.

doi:10.1186/1479-5868-10-11

Cite this article as: Kramer et al: Neighbourhood safety and leisure-time physical activity among Dutch adults: a multilevel perspective.

International Journal of Behavioral Nutrition and Physical Activity 2013 10:11.

\section{Submit your next manuscript to BioMed Central and take full advantage of:}

- Convenient online submission

- Thorough peer review

- No space constraints or color figure charges

- Immediate publication on acceptance

- Inclusion in PubMed, CAS, Scopus and Google Scholar

- Research which is freely available for redistribution 